\title{
Geriatric health in Bangladesh during COVID-19: challenges and recommendations
}

\author{
Md Mahbub Hossain MBBS MPH, a* $^{*}$ Hoimonty Mazumder MBBS MPS MPH, \\ Samia Tasnim MBBS, ${ }^{\text {a }}$ Tasmiah Nuzhath MSS, ${ }^{a}$ Abida Sultana MBBSc
}

\begin{abstract}
The novel coronavirus disease (COVID-19) is impacting health globally, whereas older adults are highly susceptible and more likely to have adverse health outcomes. In Bangladesh, the elderly population has been increasing over the past few decades, who often live with poor socioeconomic conditions and inadequate access to healthcare services. These disparities are likely to increase amid COVID-19, which may result in high mortality and morbidity among Bangladeshi older adults. We recommend that multifaceted interventions should be adopted for strengthening social care and health systems approach to ensure wellbeing, promote preventive measures, and facilitate access to healthcare among older adults in Bangladesh. Such multipronged measures would require policy-level commitment and collaborative efforts of health and social care providers and institutions to protect health and wellbeing among this vulnerable population during the COVID-19 pandemic.
\end{abstract}

Keywords: Aging; Geriatrics; Older Adults; COVID-19; Coronavirus; Bangladesh

\footnotetext{
a. Department of Health Promotion and Community Health Sciences, Texas A\&M School of Public Health, College Station, TX 77843, USA.

b. Ipas Bangladesh, Dhaka, Bangladesh.

c. Gazi Medical College, Khulna, Bangladesh.

*Corresponding author: Md Mahbub Hossain MBBS MPH, Department of Health Promotion and Community Health Sciences, Texas A\&M School of Public Health, College Station, TX 77843, USA. Email:

mhossain@tamu.edu
} 
The novel coronavirus disease (COVID-19) is a major global health concern, especially for older adults who share a major proportion of mortality and morbidity in this pandemic (World Health Organization, 2020a). COVID-19 imposes unique challenges to low- and middle-income countries (Mazumder, Hossain, \& Das, 2020), leaving Bangladesh with no exception. It is the eighth-most populous country in the world, with more than 162 million population (World Health Organization, 2020b). In 2016, the life expectancy of Bangladeshi males and females became 71 and 74 years, respectively (World Health Organization, 2020b), which is much higher than a national average of 46.5 years in 1971 when the country got independence (The World Bank, 2019). This can be attributable to notable success in terms of reducing child and maternal mortality, infectious diseases, and malnutrition in the past 49 years, which is also known as Bangladesh Paradox (Hossain, Sultana, \& Munzur-E-Murshid, 2018). However, despite a significant improvement in the overall population health and increased life expectancy, geriatric health problems are still under-recognized in Bangladesh (Barikdar, Ahmed, \& Lasker, 2016). In this article, we describe unique challenges for Bangladeshi older adults during COVID-19 and discuss potential strategies addressing the same.

In the sociocultural context of Bangladesh, older adults are generally dependent on their family members, which limits the autonomy and abilities for decision-making regarding their own health (Ellickson, 1988). This critically affects their health and quality of living. During COVID-19, socioeconomic challenges like unemployment and poverty are increasing in Bangladesh (The World Bank, 2020), which is impacting the householders as well as older adults living with their families. Moreover, in the absence of an organized and universal social care program, Bangladeshi older adults continue to experience the indirect socioeconomic burden of COVID-19.

Another critical challenge is the high burden of noncommunicable diseases among older adults in Bangladesh (Mazumder, Murshid, Faizah, \& Hossain, 2020; Taskin, Biswas, Siddiquee, Islam, \& Alam, 2014). As the health outcomes of COVID-19 is poorer among people with preexisting conditions (World Health Organization, 2020a), Bangladeshi older adults remain highly vulnerable to adverse health outcomes in this pandemic. 
Furthermore, as the country is experiencing community transmission of COVID-19 (UN News, 2020), community-dwelling older adults are highly susceptible to the infection and associated mortality.

Lastly, older adults in Bangladesh may lack mobility and access to care amid COVID-19. As the nation has no home-based care program for older adults, seeking institutional services remain the only option for someone who is experiencing any kind of health problems. Moreover, nationwide travel restrictions and limited availability of transportations during this pandemic have made it difficult to access healthcare centers that are located mainly in the urban areas, whereas more than sixty-three percent of the population lives in rural areas of Bangladesh (The World Bank, 2016). In addition, many of the tertiary care centers are transforms into COVID-19 hospitals, where access to regular care services has become limited (Dhaka Tribune, 2020). Therefore, older adults in Bangladesh are less likely to receive timely and appropriate care for COVID-19 and other health problems.

These challenges highlight some of the major challenges that Bangladeshi older adults are experiencing amid COVID-19. Many of those can be explained by evaluating the preexisting health disparities for older people, whereas some of them are aggravating as COVID-19 has impacted socioeconomic conditions and health systems. As more people are approaching to elderhood as well as increased susceptibility to COVID-19, these challenges should be considered for effective policymaking ensuring better health and social care for older adults in Bangladesh. We propose the following recommendations for strengthening geriatric care during COVID-19 in Bangladesh:

1. Introducing a comprehensive health and social care program for older adults who are dependent on their families or have no sources of income

2. Strengthening existing social care programs that directly or indirectly support older adults based on the special challenges during COVID-19

3. Mobilizing community resources like religious institutions and voluntary organizations to improve social care and rapid response to affected or vulnerable older adults during COVID-19 
4. Launching mass media programs like radio shows, television programs, and online events promoting education and awareness on geriatric wellbeing, self-care, and preventive measures for COVID-19

5. Initiating telemedicine services and remote health consultations for older adults

6. Educating and empowering informal caregivers to older adults to promote preventive practices and improve access to health services for older adults

7. Strengthening public health surveillance for COVID-19 among older adults with enhancing diagnostic capacities for this population

8. Improving collaborations among community health centers and advanced care facilities for effective referral and clinical care

9. Providing dedicated ambulance services for transporting suspected or diagnosed cases of COVID-19 to the nearest healthcare organization

10. Prioritizing geriatric care in health and social policymaking for COVID-19 to ensure policy-level resources and support for measures adopted by the community and institutional stakeholders

Geriatric health problems are highly prevalent in Bangladesh, whereas institutional and social capacities to address the same remain limited (Bilkis, 2020; Mazumder, Murshid, et al., 2020; Taskin et al., 2014). During the COVID-19 pandemic, these gaps may increase manifolds and result in high mortality and morbidity among older adults who are highly susceptible to infection and less likely to receive adequate care. To maintain the population health gains through preventive measures in the past decades, the policymakers and other key stakeholders must address the geriatric care needs amid the COVID-19 pandemic. Nonetheless, health and social care providers and institutions may play vital roles in policy advocacy and service delivery, promoting geriatric care during COVID-19. Bangladesh has a long history of effective public health measures despite socioeconomic challenges, which should be reinforced in decision-making processes to protect the health of the Bangladeshi older adults in the era of the COVID-19 pandemic. Funding: No funding was received at any stage of preparing this manuscript Acknowledgement: None Conflicts of interest: We declare no conflicts of interest 


\section{References}

Barikdar, A., Ahmed, T., \& Lasker, S. P. (2016). The Situation of the Elderly in Bangladesh. Bangladesh Journal of Bioethics, 7(1), 27-36. https://doi.org/10.3329/bioethics.v7i1.29303

Bilkis. (2020). Lifestyle and Depression in Urban Elderly of Selected District of Bangladesh. Retrieved April 22, 2020, from https://www.researchgate.net/publication/338514812_Lifestyle_and_Depression _in_Urban_Elderly_of_Selected_District_of_Bangladesh

Dhaka Tribune. (2020). Kurmitola General Hospital soon to treat Covid-19 patients only | Dhaka Tribune. Retrieved May 10, 2020, from https://www.dhakatribune.com/bangladesh/dhaka/2020/04/02/kurmitolageneral-hospital-soon-to-treat-covid-19-patients-only

Ellickson, J. (1988). Never the twain shall meet: Aging men and women in Bangladesh. Journal of Cross-Cultural Gerontology, 3(1), 53-70. https://doi.org/10.1007/BF00116960

Hossain, M. M., Sultana, A., \& Munzur-E-Murshid. (2018, October 1). Revitalising general practice in Bangladesh: Complementing 'the Bangladesh Paradox. British Journal of General Practice. Royal College of General Practitioners. https://doi.org/10.3399/bjgp18X699173

Mazumder, H., Hossain, M. M., \& Das, A. (2020). Geriatric Care during Public Health Emergencies: Lessons Learned from Novel Corona Virus Disease (COVID-19) Pandemic. Journal of Gerontological Social Work. Routledge. https://doi.org/10.1080/01634372.2020.1746723

Mazumder, H., Murshid, M.-E., Faizah, F., \& Hossain, M. M. (2020). Geriatric mental health in Bangladesh: a call for action. International Psychogeriatrics, 1-2. https://doi.org/10.1017/s1041610220000423

Taskin, T., Biswas, T., Siddiquee, A. T., Islam, A., \& Alam, D. (2014). Chronic NonCommunicable Diseases among the Elderly in Bangladesh Old Age Homes. 
Retrieved May 10, 2020, from https://cgscholar.com/bookstore/works/chronicnoncommunicable-diseases-among-the-elderly-in-bangladesh-old-age-homes

The World Bank. (2016). Rural population (\% of total population ) Bangladesh.

Retrieved May 10, 2020, from

https://data.worldbank.org/indicator/SP.RUR.TOTL.ZS?locations=BD

The World Bank. (2019). Life expectancy at birth, total (years) - Bangladesh | Data.

Retrieved May 10, 2020, from

https://data.worldbank.org/indicator/SP.DYN.LE00.IN?locations=BD

The World Bank. (2020). Bangladesh Must Ramp Up COVID-19 Action to Protect its

People, Revive Economy. Retrieved May 10, 2020, from

https://www.worldbank.org/en/news/press-release/2020/04/12/bangladesh-

must-act-now-to-lessen-covid-19-health-impacts

UN News. (2020). From bustling streets to lockdown: Bangladesh and the UN mobilize to fight COVID-19: a UN Resident Coordinator blog | | UN News. Retrieved May 10, 2020, from https://news.un.org/en/story/2020/04/1062552

World Health Organization. (2020a). Statement - Older people are at highest risk from COVID-19, but all must act to prevent community spread.

World Health Organization. (2020b). WHO Bangladesh Country Profile. WHO. 